\title{
ЭКОНОМИЧЕСКИЕ И ИНСТИТУЦИОНАЛЬНЫЕ ИНТЕРЕСЫ И ИХ РОЛЬ В СИСТЕМЕ ХОЗЯЙСТВЕННЫХ ОТНОШЕНИЙ
}

\author{
(C) 2018 Мишин Алексей Юрьевич \\ Руководитель подкомитета по защите прав кредиторов \\ Комитета по финансовым услугам Деловой России \\ Общероссийская общественная организация «Деловая Россия» \\ 119121, Москва, 2-й Вражский переулок, д. 1 \\ E-mail: alink2501@gmail.com
}

В статье рассматриваются методологические и теоретические подходы к исследованию экономических и институциональных интересов участников системы хозяйственных отношений, выявляется неразрывная связь и противоречивый характер взаимодействия экономических и институциональных интересов экономических акторов.

Ключевые слова: интерес, потребность, экономический интерес, институциональный интерес, хозяйственная система

Как известно, «локомотивом» любой хозяйственной системы, двигающим ее вперед, вызывающим постоянное развитие, сопровождающееся трансформацией социально-экономических отношений, являются противоречивые интересы ее участников. Разрешение противоречий невозможно в условиях непонимания природы интереса как социально-экономического явления, некой потенции, наделяющей человеческую деятельность смыслом, определяющей вектор ее движения или, другими словами, причинно-следственные связи той или оной модели социального поведения.

Категория «интерес» привлекла к себе авторов еще в глубокой древности, в достаточно примитивной форме можно встретить рассуждения философов далеких эпох, таких как Аристотель, Платон, Конфуций, о природе интересов рабов и рабовладельцев, лиц, стоящих у власти, и тех, кто вынужден беспрекословно подчиняться им, зажиточных и неимущих.

Интерес как категория часто рассматривается через призму социологии, психологии, философии, и ряда иных гуманитарных наук, в том числе и экономики, причем каждая из областей знания «раскрашивает» термин в цветах своей палитры. То можно встретить определение, где под интересом понимается не что иное, как «внимание, возбуждаемое к кому (чему)-нибудь значительному, важному, полезному или кажущемуся таковым» [9], то его определяют в качестве меры удовольствия, избавляющего нас от страдания, считая, что мир духовный подчинен закону интереса [2]. Много споров об объектив- ной и субъективной природе интересов, рождаются ли интересы вне нас, и мы как зеркало их отражаем, или напротив, источник интересов сознание, и, в таком случае, интерес - продукт нашего духовного бытия. Не вдаваясь в полемику, поскольку это мало плодотворно, любая область научная знания выстраивает модель окружающего нас мира и нас самих в нем в рамках собственной системы координат, практически не совместимой с другими науками, сконцентрируем свое внимание на понимании данной категории в рамках экономических исследований.

Экономическая наука, несмотря на зачатки ее в глубокой древности, является сравнительно молодой, начало XVII века, период бурного промышленного развития, стал той точкой отсчета, с которой берет начало первая экономическая школа - классическая политическая экономия. Ее основоположники, У Петти, Ф. Кенэ, А. Тюрго, А. Смит, Д. Рикардо и многие другие, рассуждают об интересах в тесной связи с процессами промышленного производства. Важнейший интерес, причем речь идет именно об экономическом интересе, с позиции данных авторов,это накопление богатства, или перефразировав А. Смита, можно сказать, что - это стремление к получению собственной выгоды, в то время как последняя материализуется в виде экономических благ.

Модель экономического человека в классической политической экономии выстраивается на постулате основополагающей роли экономического интереса хозяйствующего субъекта 
в мотивации его поведения. И несмотря на название - концепция «экономического эгоиста», данная модель описывает вовсе не разрушительную, а, напротив, созидательную функцию индивидуального интереса, приводящего систему экономических отношений в движение, заставляющего ее развиваться, и речь идет не только об экспансии процесса обмена, но и всех остальных фаз процесса производства, их трансформации под действием научно-технического и социального прогресса.

В марксистской теории, базирующейся на идеях классиков, поиск баланса индивидуального и общественного интересов, поднятый в работах А.Смита и Д.Рикардо, микшируется, уходит на второй план. Речь идет не об эгоистических интересах личности, стремящейся к получению выгоды, масштаб становится крупнее, во главу угла попадают общественные экономические интересы, интересы классов, крупных социально-экономических групп. При этом связь интересов с производственными отношениями только усиливается, в то время как социально-психологический налет в понимании интереса, описанный Й.Бентамом и так ярко популяризированный его другом А. Смитом в труде «Исследование о природе и причинах богатства народов», практически исчезает. Марксистская модель экономического человека - это макромодель, ее игроки обезличены, главные роли играют макроагрегаты - наемный рабочий и капиталист. Частные интересы - это не порождение природы человека, а отражение общественного интереса, который носит объективный характер. В подобного рода рассуждениях нет ничего удивительного, поскольку марксизму как течению свойственно совершенно иная философская парадигма - материализм, а, следовательно, сознание (как индивидуальное, так и общественное) всего лишь копия общественного бытия. Окружающая действительность, преломляясь в сознании отдельных индивидов, может вызывать дефекты в их восприятии, когда личные интересы не соответствуют своему объективному содержанию. Но это исключение их правил, а вовсе не правило. Марксисты, абстрагируясь от различий во вкусах и желаниях отдельных хозяйствующих субъектов, уверены, что в целом, в рамках всего общества, поведение людей определяется действием объективных экономических интересов $[4,5,8]$.

Вторая половина XIX века ознаменовалась не только развитием идей марксизма, но и зарождением такого нового течения как маржинализм, причем последний находится в состоянии непримиримой борьбы с марксистскими идеями, а, следовательно, полностью игнорирует классовый подход, поднимая на пьедестал принцип индивидуализма. Муссируя вопрос классификации человеческих потребностей, психологической природы человека, маржиналисты констатируют субъективную природу экономических интересов. Экономические интересы это внутренние побудительные силы, которые определяют направления действий субъектов, в том числе и в процессе производства материальных благ и услуг.

Несмотря на столь широкий междисциплинарный подход к исследованию природы экономических интересов субъектов, модель экономического человека в рамках маржинализма, более лаконична, чем в классической политической экономии. Смитовский экономический эгоист по своей сути весьма противоречивая натура, в которой рациональные аспекты деятельности человека переплетены с его эмоциональной составляющей, человеку свойственны ошибки, он постоянно борется с собой в поиске баланса общественных и индивидуальных интересов. Маржиналисткая модель - это модель оптимизатора. Человек сродни роботу, абсолютно рационален, а, следовательно, не способен ошибаться. Пытаясь вогнать теоретическую конструкцию в жестко заданные рамки математической модели, маржиналисты, как, впрочем, и марксисты в рамках использования метода агрегирования, отрываются от реальности, создавая идеальные конструкции, часто противоречащие экономическим реалиям. Обилие ограничений, в одном случае с формулировкой при прочих равных условиях, в другом - путем восхождения от конкретного к абстрактному, от сложного к простому, вплоть до использования метода редукции труда, превращает экономический интерес в однофакторную математическую функцию либо класса, либо отдельно взятого индивида.

Недостаток в исследованиях проблемы экономических интересов второй половины XIX века, на наш взгляд, можно объяснить тем, что обе теории, несмотря на декларацию разной природы экономических интересов, анализ самих интересов уводят на второй план, в попытке выяснит причину рождения экономического 
интереса, забывают об ответе на вопрос, а что же этот интерес представляет сам по себе, какова его сущность и содержание, которые явно не могут быть однобокими. Сама биосоциальная природа человека свидетельствует о том, что человек имеет обоюдно направленную связь с обществом, как он воздействует на социум, так и социум воздействует на него. Эта мысль начала приобретать четкие очертания в немецкой исторической школе, а в последующем громко зазвучала в рамках институционализма.

Человеческое поведение включает в себя два момента: субъективную мотивацию индивида, в основе которой лежит удовлетворение его потребностей, и ориентацию на других, М. Вебер, последнею называет ожиданием [1]. Сочетание объективной и субъективной реальности в процессе принятия решений и совершения действий индивидов лишний раз подчеркивает неоднородность интереса как категории, ведь на ряду с экономическими интересами явно присутствуют и институциональные интересы хозяйствующих субъектов.

Интерес является порождением нашей человеческой природы. В этой связи нам кажется корректным определение О. Шика, который отмечает, что любой недостаток чего-то (потребность), ощущаемый человеком отражается в его сознании и вызывает стремление к устранению этого недостатка. Если это стремление начинает носить концентрированный, относительно устойчивый характер, полностью переключая внимание человека на удовлетворение определенных потребностей, то его можно назвать интересом [10].

В данном определении О.Шика подчеркивается такая ключевая черта интереса как относительная устойчивость направленности внимания человека на удовлетворение потребности, но это отнюдь не единственная черта. Проявляясь в сознательной деятельности людей, интерес всегда является формой отражения потребности, он конкретизирован. В интересе присутствует не только осознанная потребность, но и форма ее удовлетворения, а, следовательно, есть не только субъект интереса (его носитель), но и объект интереса (то, на что направлено внимание, в чем заинтересован субъект). Не вызывает сомнение и наличие в интересе движущей побудительной силы, «спускового крючка» $\mathrm{k}$ действию, из-за чего нередко в научной литературе интерес называют направлен- ной, векторной категорией [6, 7]. Многомерность такой социально-экономической категории как интерес не позволяет ее рассматривать как синоним к термину «потребность», выступающей в качестве источника, причины возникновения интереса. Функционал этих категорий различен, потребности свойственны каждому индивиду не зависимо от его социального статуса и роли, они выступают доказательством биосоциальной природы самого человека, в то время как интересы характеризуют субъекта как участника системы общественных отношений, определяются местом индивида в этой системе.

Интересы весьма разнообразны, и не все интересы являются экономическими. По мнению А. Гоша, и мы с ним солидарны, экономические интересы определяют направление действий экономических акторов в процессе производства материальных благ и услуг [3]. Роль производственных отношений сводится к тому, что это та сфера, та объективная реальность, которая накладывает на механизм зарождения интереса отпечаток своей специфики. «Экономические интересы - это не отношения между людьми, а форма проявления экономических отношений в действиях субъектов. ... Через экономические интересы осуществляется действие экономических законов» [6].

Пользуясь логикой неоклассики, мы могли бы дополнить наши рассуждения об экономических интересах, следующим выводом. Если доступ к благам не ограничен, и они участвуют в процессе распределения без всяких препятствий, то по отношению к этим благам не возникает экономических интересов. Принцип ограниченности ресурсов является базовым при определении сути экономического интереса.

Институциональные интересы имеют аналогичную природу экономическим, но сфера их проявления иная. Реализация институционального интереса предполагает выработку норм и правил деятельности индивидов, которые нацелены на стабилизацию хозяйственной системы, удержание ее в рамках пусть и относительного, но равновесия. Потребность в безопасности и выше стоящие, согласно пирамиде А. Маслоу, социальные и духовные потребности не могут быть удовлетворены в условиях хаотичного взаимодействия субъектов социума. Требуется институциональное поле в форме норм морали, права, религии, которое позволит субъектам сосуществовать в мире и согласии, пусть и частич- 
но ущемив их свободы.

Наличие институциональных интересов также, как и экономических,- это неотъемлемый атрибут развития хозяйственных отношений. Сосуществуя в единстве и в постоянной борьбе друг с другом, экономические и институциональные интересы позволяют получить достаточно предсказуемую траекторию будущих трансформаций экономической системы, повысить уровень благосостояния ее элементов, в качестве которых выступают хозяйствующие субъекты. Пользуясь методом аналогии, мы могли бы сказать, что институциональные и экономические интересы, сродни физическим силам. Одни (институциональные) удерживают «планету» хозяйственных отношений, не позволяя ей разлететься на мелкие кусочки, другие (экономические) заставляют ее вращаться не только вокруг своей оси, но и по более широкому радиус, что способно гарантировать ее развитие. В идеале, в условиях достигнутого баланса экономических и институциональных интересов, можем наблюдать рост доходов всех участников экономической деятельности, повышение транспарентности экономической среды, снижение координационных и трансакционных издержек участников рыночных отношений.

\section{Библиографический список}

1. Вебер М. Основные социологические понятия / Избр. произведения: пер. с нем. Москва. 1990.

2. Гельвеций К.А. Об уме // Соч.: в 2 т. Т. 1. Москва. 1973.

3. Гош А. Материальные потребности и экономические интересы // Экономические науки. 1971. № 7.

4. Ленин В.И. Материализм и эмпириокритицизм/ Полн. собр. соч. $\quad$ Москва. 1967-1981. Т.18.

5. Маркс К. Экономические рукописи 1857-1859 годов / К. Маркс, Ф. Энгельс Соч. 2-е изд. Т.46. Ч.1.

6. Михайлов А.М. Проблемы реализации экономических и институциональных интересов собственников факторов производства. Москва. 2006.

7. Осауленко И.В. Тенденции структурных сдвигов в системе экономических интересов предприятия: дис.... канд. экон. наук. Тамбов, 2002.

8. Плеханов Г.В. Избранные философские произведения. Москва. 1956. Т. 2.

9. Советский энциклопедический словарь/ Под ред. А. М. Прохорова. Москва. 1990.

10. Шик О. Экономика. Интересы. Политика. Москва. 1964. 